Www.jmscr.igmpublication.org

Index Copernicus Value: 79.54

ISSN (e)-2347-176x ISSN (p) 2455-0450

crossref DOI: https://dx.doi.org/10.18535/jmscr/v7i6.156

\title{
Clinico Pathological Study and Management of Benign Breast Disease
}

\author{
Authors

\section{Dr N.Shanmuga Sankar Ram ${ }^{1 *}$, Dr S. Navaneetha Krishnan ${ }^{2}$, Dr N. Junior Sundresh ${ }^{3 *}$} \\ ${ }^{1,3}$ Professor, Department of Surgery, R.M.M.C.H, Annamalai University \\ ${ }^{2}$ Assistant Professor, Department of Surgery, R.M.M.C.H, Annamalai University \\ *Corresponding Author
}

Dr. N. Junior Sundresh

Professor, Department of Surgery, R.M.M.C.H, Annamalai University

\begin{abstract}
Aim: The aim of the study is to analyze the incidence, mode of presentation of Benign Breast Disease, Clinical \& pathological correlation of benign breast disease, and to Study \& compare various modes of management.

Materials and Methods: The study of benign breast lumps includes random selection of a total of 50 cases. Besides the routine investigations Fine Needle Aspiration Cytotogy (FNAC) was done in almost all the cases. The follow up of the prospective cases were re-examined at the hospitals. 20 patients returned to the hospital for follow-up. The follow-up included recording of the patients' symptoms and clinical findings related to recurrent breast lumps. At the end of the study period and follow-up the material was analysed and the results were tabulated. The test of significance used in the statistical analysis was the proportion test.

Conclusion: The findings of this clinico-pathological study of benign breast lumps collaborates with the findings of earlier works in most aspects, but differs with respect to the management of fibroadenomas in teenagers.
\end{abstract}

Keywords: Benign Breast Disease, Fine Needle Aspiration Cytotogy (FNAC), breast lumps, and fibroadenomas.

\section{Introduction}

Benign breast disease is a common disorder. It is commoner than breast malignancy (Marsel, 1992), accounting to majority of patients presenting with breast symptoms. The ratio of benign disease to malignancy being 1O:1 (Barclay et al, 1991). ${ }^{1}$

The disease encompasses wide spectrum of clinico-pathological changes from near normality to severe disease. Up to $33 \%$ of women suffer from benign breast disease at some or other time in their lives. ${ }^{2}$
The term fibrocystic disease or other misnomers are absolute now with new concept of ANDI; i.e. these diseases are considered as aberrations in normal development and involution process of breast. Thus, the fibroadenoma is an over growth of fibrous stromain early reproductive or developmental age and a breast cyst represents a failure to undergo involution smoothly. ${ }^{3-5}$

This entity remained neglected until now because of confusing terminology, wide spectrum of 
pathological changes, more subjective symptoms compared to clinical findings. ${ }^{6}$

Benign breast disease is an important area both because of its incidence in the population at large and because of the concern it generates. This combination accounts for many referrals to a specialist breast clinic, some of which are inappropriate. $^{7}$

The main problem from the patient's point of view is the intense anxiety associated with any symptom related to the breast, due to fear of cancer. Anxiety aside, serious cosmetic problems may result from repeated small biopsies or removal of breast quadrants in an attempt to search for small mammographic abnormalities. A minority of patients presenting with mastalgia, in spite of being reassured that cancer is not present, will, nevertheless continue to suffer from severe cyclical pain, which is a problem in its own right. ${ }^{8}$ With recent studies indicating risk of malignant changes in benign breast disease and awareness of carcinoma breast among patients, need for differentiation of benign breast disease from malignancy have attracted increasing interest in benign breast disease. ${ }^{9}$

\section{Materials and Methods}

The study of benign breast lumps includes random selection of a total of 50 cases during the period
March 1999 to February 2OOl. Only those patients who presented with breast symptoms to Department of Surgery in Bowring \& Lady Curzon Hospital formed part of the study. ${ }^{10}$

The details of age, sex, nature and duration of symptoms, menstrual and obstetric history and the clinical finding (Number, Site and size of the lumps, associated lymphadenopathy etc.) were recorded in a proforma. Enquiry was also made regarding use of oral contraceptives and previous surgery for a breast lump. Besides the routine investigations Fine Needle Aspiration Cytotogy (FNAC) was done in almost all the cases. The details of surgery and FNAC were available in all the cases.

The follow up of the prospective cases were reexamined at the hospitals. 20 patients returned to the hospital for follow-up. The period of followup ranged from 3 to 18 months (mean 8 months) depending on the time of entry, into the study. The follow-up included recording of the patients' symptoms and clinical findings related to recurrent breast lumps. At the end of the study period and follow-up the material was analysed and the results were tabulated. The test of significance used in the statistical analysis was the proportion test. $^{11-14}$

\section{Observation and Analysis of Results}

This study includes a total of50 cases were studied prospectively over a period of two years.

Table - I Age Incidence

\begin{tabular}{|l|c|c|c|c|c|}
\hline & \multicolumn{6}{|c|}{ Age Groups (in years) } \\
\hline Diagnosis & $\mathbf{1 1 - 2 0}$ & $\mathbf{2 1 - 3 0}$ & $\mathbf{3 1 - 4 0}$ & $\mathbf{4 1 - 5 0}$ & $\mathbf{5 1 - 6 0}$ \\
\hline Fibroadenoma & 10 & 9 & 7 & 1 & 0 \\
\hline Fibroadenosis & 0 & 10 & 0 & 0 & 0 \\
\hline Cystosarcoma & 0 & 0 & 2 & 0 & 0 \\
\hline Galactocele & 0 & 2 & 0 & 0 & 0 \\
\hline Inflammatory & 0 & 1 & 0 & 2 & 0 \\
\hline Gynaecomastia & 2 & 0 & 0 & 0 & 0 \\
\hline Others & 0 & 1 & 1 & 1 & 1 \\
\hline Total & $\mathbf{1 2 ( 2 4 \% )}$ & $\mathbf{2 3 ( 4 6 \% )}$ & $\mathbf{1 0}(\mathbf{2 0 \%})$ & $\mathbf{4 ( 8 \% )}$ & $\mathbf{1 ( 2 \% )}$ \\
\hline
\end{tabular}

Among the entire 50 cases there were only two male patients admitted for gynaecomastia. All others were women. On the whole, over $7 \%$ of the benign breast lumps presented is the second and third decades of life. The number of lesions in the third decade $(46 \%)$ of the total was significantly higher than the other age groups. There was only I patient $(2 \%)$ whose age was more than fifty. The 
youngest patient was a boy aged 13 years with gynaecomastia and the oldest patient in the study was a female patient who presented with lump in the lower outer quadrant was later diagnosed as sclerosingadenosis on histopathological examination of the excised lump at the age of 58 years. The majority of the fibroadenoma $(70 \%)$ present in the age group of 11 to 50 years. However, almost $100 \%$ of the patients with fibroadenosis presented a decade later between 20 and 40 years of age. Regarding the solitary cystosarcoma phyllodes it presented in the third and fourth decade of life. Gynaecomastia was common in adolescence. Mean age group for benign breast disease in this study was 26 years.

Table - II Distribution of cases

\begin{tabular}{|l|c|c|c|}
\hline S. No & Lesion & $\begin{array}{c}\text { No. of } \\
\text { cases }\end{array}$ & $\begin{array}{c}\text { Percentage } \\
(\%)\end{array}$ \\
\hline 1 & Fibroadenoma & 27 & 54 \\
\hline 2 & Fibroadenosis & 10 & 20 \\
\hline 3 & $\begin{array}{c}\text { Cystosarcoma } \\
\text { phylloides }\end{array}$ & 2 & 4 \\
\hline 4 & Galactocele & 2 & 4 \\
\hline 5 & Smple cyst & 2 & 4 \\
\hline 6 & Non lactating breast & 2 & 4 \\
\hline 7 & abscess & 2 & 4 \\
\hline 8 & Gynaecomastia & 1 & 2 \\
\hline 9 & Antibioma & 1 & 2 \\
\hline 10 & Dclerosing adenosis & 1 & 2 \\
\hline
\end{tabular}

The majority of the Lesions in this study were fibroadenoma accounting for $54 \%$ of the 50 cases. Fibrocystic disease, most often termed as fibroadenosis in this study, was the second largest group forming (20\%) of the cases. There were 2 cases of cystosarcoma phylloides. Less common conditions include 2 cases of galactocele, 2 cases of chronic mastitis, 2 cases of simple cyst, 2 cases of duct ectasia and one case of antibioma, sclerosingadenosis \& ductal hyperplasia each. No cases of tuberculosis, Mondor's disease, Fat necrosis, Schwannoma or Actinomycosis was included in this study.

\section{Etiology}

History of use of oral contraceptive pills could be obtained only from 10 cases. Only 10 patients had used oral contraceptive pills in the past and none of the patients in the study were on pills at the time of presentation.

\section{Clinical Features}

Table III (A) Mode of Presentation

\begin{tabular}{|l|c|c|}
\hline Symptom & No. of cases & Percentage \\
\hline Lump & 40 & $80 \%$ \\
\hline Mastalgia & 12 & $24 \%$ \\
\hline Nodularity & 8 & $16 \%$ \\
\hline Discharge & 4 & $8 \%$ \\
\hline
\end{tabular}

A lump in the breast was the predominant symptom (80\%). Only 9 patients (18\%) did not notice any lump, but complained of nodularity and had fibroadenosis (Table - III A). pain, the next common symptom was present in $(24 \%)$ of the patients. Almost $80 \%$ of the patients with fibroadenosis complained of pain whereas only $29 \%$ of the patient with fibroadenoma had pain. Relationship of pain to menstruation was noted in $28 \%$ of painful fibroadenomata and $31 \%$ of painful fibroadenosis. 20 (4oo/al of the patients presented with symptoms of less than one year duration. 9 (18\%) had symptoms for less than a month, whereas $21(42 \%)$ had symptoms for more than one year.

Table III (B) Duration of Symptoms

\begin{tabular}{|l|c|c|c|c|}
\hline & \multicolumn{4}{|c|}{ Duration of Symptoms } \\
\hline Lesion & $<\mathbf{1}$ & $\mathbf{1 - 6}$ & $\mathbf{7 - 1 2}$ & $>\mathbf{1 2}$ \\
\hline Fibroadenoma & 7 & 11 & 0 & 9 \\
\hline Fibroadenosis & 0 & 1 & 0 & 9 \\
\hline $\begin{array}{l}\text { Cystosarcoma } \\
\text { phylloides }\end{array}$ & 0 & 2 & 0 & 0 \\
\hline Galactocele & 0 & 2 & 0 & 0 \\
\hline Gynaecomastia & 2 & 0 & 0 & 0 \\
\hline Cyst & 0 & 2 & 0 & 0 \\
\hline Others & 0 & 2 & 0 & 3 \\
\hline Total & $\mathbf{9}$ & $\mathbf{2 0}(\mathbf{4 0 \%})$ & - & $\mathbf{2 1}$ \\
$\mathbf{( 4 2 \% )}$
\end{tabular}

Table IV Nipple Discharge as Symptoms

\begin{tabular}{|l|c|c|}
\hline Lesion & No. Of cases & Percentage \\
\hline Fibroadenoma & - & - \\
\hline Fibroadenosis & $2 / 10$ & $20 \%$ \\
\hline Duct Ectasia & $1 / 2$ & $50 \%$ \\
\hline Galactocele & $1 / 2$ & $50 \%$ \\
\hline Total & $4 / 50$ & $8 \%$ \\
\hline
\end{tabular}

The longest duration of symptoms at presentation was noted in48 years old women with a ductal hyperplasia of twenty years (Table III B). Nipple 
discharge was present in only 4 out of 50 (Table IV) cases, whereas a serious or dark brown discharge was observed in two cases of fibroadenosis and one case of milky discharge. In this study, it was found that those with fast growing lumps presented earliest within two months of the onset of symptoms.

Table V Right v/s Left Distribution of Lumps

\begin{tabular}{|l|c|c|c|}
\hline Diagnosis & \multicolumn{3}{|c|}{ Side } \\
\hline Diagnosis & Right & Left & Both \\
\hline Fibroadenoma & 13 & 10 & 4 \\
\hline Fibroadenosis & 3 & 2 & 5 \\
\hline Cystosarcoma phylloides & 1 & 1 & 0 \\
\hline Galactocele & 0 & 2 & 0 \\
\hline Smple cyst & 2 & 0 & 0 \\
\hline Gynaecomastia & 2 & 0 & 0 \\
\hline Inflammatory & 1 & 2 & 0 \\
\hline Others & 1 & 1 & 0 \\
\hline Total & $\mathbf{2 3 ( 4 6 \% )}$ & $\mathbf{1 8 ( 3 6 \% )}$ & $\mathbf{9 ( 1 8 \% )}$ \\
\hline
\end{tabular}

Details regarding parity and menstruation were available in most of the cases. Menstrual abnormalities like dysmenorrhea, menorrhagia etc., were present in 20\%. Most patients also complained of premenstrual breast pain. The type of benign lumps, were however related neither to the parity nor to the menstrual disturbances. There was a slight but insignificant preponderance of lesions in the right breast as compared to the left (Table-V). $46 \%$ of the lesions were located in the right breast whereas $\mathrm{j} 6 \mathrm{o} / \mathrm{o}$ were situated in the left breast and I B0/o bilaterally. The Lumps obeyed the established clinical features except when previous surgery restricted mobility or caused skin adherence.

Table VI Quadrant-wise Distribution of Lumps

\begin{tabular}{|l|c|c|}
\hline Quadrant & No. of cases & Percentage \\
\hline Upper outer & 25 & $50 \%$ \\
\hline Lower outer & 13 & $26 \%$ \\
\hline Upper Inner & 5 & $10 \%$ \\
\hline Lower Inner & 1 & $2 \%$ \\
\hline Subareolar & 5 & $10 \%$ \\
\hline$>1$ Quadrant & 1 & $2 \%$ \\
\hline
\end{tabular}

Table VII Number of Lumps per case

\begin{tabular}{|l|c|c|}
\hline $\begin{array}{l}\text { Number of } \\
\text { lumps }\end{array}$ & No. of cases & Percentage \\
\hline One & 31 & $62 \%$ \\
\hline Two & 7 & $14 \%$ \\
\hline Three & 2 & $4 \%$ \\
\hline Four & - & - \\
\hline
\end{tabular}

Table VIII Size of Lumps

\begin{tabular}{|l|c|c|}
\hline Size & No. of cases & Percentage \\
\hline Upto $2 \mathrm{~cm}$ & 12 & $24 \%$ \\
\hline 2 to $5 \mathrm{~cm}$ & 27 & $54 \%$ \\
\hline$>5 \mathrm{~cm}$ & 11 & $22 \%$ \\
\hline
\end{tabular}

The quadrant wise distribution of the lumps (Table - VI) showed an excess of lesions in the upper half of the breast especially the upper and outer quadrant $50 \%$ of the lumps were found to occupy this quadrant while $10 \%, 26 \%$ and $2 \%$ were located in the upper inner, lower outer and lower inner quadrant respectively. The remainder $(10 \%)$ was found in the sub areolar region and $2 \%$ occupied more than one quadrant.

$62 \%$ of the patients had only solitary lump. The other patients include $14 \%$ with two lumps, $4 \%$ with 5 Lumps in (Table-VII). Bilateral diffuse granularity was noted in $80 \%$ of the patients in the fibroadenosis on histopathology. Amongst those with fibroadenoma B patients had more than one Lump at presentation whereas the corresponding figure for fibroadenoma was 2 (Table-VII).

Majority of the lumps (54\%) had a size of 2 to $5 \mathrm{cms}$ (Table-VIII). The size of the lump was large in the benign cystosarcoma group $(15 \times \mathrm{I} 0 \mathrm{x} 10 \mathrm{~cm})$, but the largest lump in the fibro adenoma group was seen in a 19-year-old girl with $8 \times 6 \mathrm{~cm}$ fibro adenoma on the right side. Among the other lumps, antibioma presented with hard lump mimicking malignancy. Calactocele presented with firm swelling and were diagnosed on aspiration. Lymph nodes were palpable in $2 \mathrm{a} / \mathrm{o}$ of the cases on the same side as the lumps. The lymph nodes were distributed uniformly among the various subgroups of lumps. Two cases of breast abscess were treated one of which had previous diagnosis of ductectasia.

\section{Mammography}

Mammography being expensive investigation was performed in selective cases, the criteria being higher age group (beyond 4th decade) and clinically doubtful lesions.

In this series mammography is available in 5 cases. In one case mammography was done elsewhere and report was suggestive of fibro 
adenoma. The report in other 3 cases was features suggestive of benign lesion and final diagnosis were cystosarcomaphylloides, fibro adenoma and fibroadenosis respectively. In one case mammography was done to know progression of lump size, which was diagnosed as fibro adenoma and was conservatively managed.

\section{Fine needle aspiration cytology}

Table - IX Accuracy of Fine needle aspiration cytology (FNAC)

\begin{tabular}{|l|c|c|c|}
\hline \multirow{2}{*}{ Diagnosis } & \multirow{2}{*}{$\begin{array}{c}\text { No. of } \\
\text { Cases }\end{array}$} & \multicolumn{2}{|c|}{ FNAC } \\
\cline { 3 - 4 } & & Consistent & $\begin{array}{c}\text { Non } \\
\text { consistent }\end{array}$ \\
\hline Fibroadenoma & 27 & $22(81.5 \%)$ & $5(18.5 \%)$ \\
\hline Fibroadenosis & 10 & $7(70 \%)$ & $3(30 \%)$ \\
\hline
\end{tabular}

Fine needle aspiration cytology (FNAC) was done in almost all the cases in this study, of the 27 cases of fibroadenoma for which FNAC was done, the diagnosis was suggested in $81.5 \%$ of the cases. The corresponding figure for fibroadenosis was $70 \%$, One case of benign cystosarcoma was diagnosed by FNAC. Antibioma showed inflammatory cells in FNAC. There was no false positive cytologic diagnosis of malignancy in the cases analyzed.

\section{Management}

Table X Conservative Management

\begin{tabular}{|l|c|}
\hline Lesion & No. Of cases \\
\hline Fibroadenoma & 7 \\
\hline Fibroadenosis & 5 \\
\hline Smple cyst & 2 \\
\hline Gynaecomastia & 1 \\
\hline
\end{tabular}

Five cases of fibroadenoma, seven cases of fibroadenosis, Two cases of simple cyst and One case of gynaecomastia were managed by conservative measures (Table, $\mathrm{X}$ ).

Selected cases of fibroadenoma of less than $2 \mathrm{~cm}$ in size were reassured and asked for regular follow up. The size of lump was noted on every visit. Out of five cases followed upto six months, three case showed no increase in the size of the lump, though, no regression in the size was noted. Two cases did not turn up for follow-up.

Conservative management of breast pain and nodularity was in the form of reassurance, dietetic changes, and avoidance of oral contraceptive pills. These patients were put on a course of capsule Evion i.e. Vitamin E preparation for three months, which was continued for next three months, if required. No hormonal therapy was administered in any of these cases. Three cases had excellent results with no pain and two of the patients had bearable pain at the end of follow-up ranging from three months to one year. Two cases showed poor response with residual pain.

\section{Surgical Management}

Table XI Type of Surgery performed

\begin{tabular}{|l|c|c|c|c|}
\hline Lesion & Excision & $\begin{array}{c}\text { Sub-cutaneous } \\
\text { Mastectomy }\end{array}$ & $\begin{array}{c}\text { Simple } \\
\text { Mastectomy }\end{array}$ & $\begin{array}{c}\text { Incision \& } \\
\text { Drainage }\end{array}$ \\
\hline Fibroadenoma & 22 & - & - & - \\
\hline Fibroadenosis & 3 & - & - & - \\
\hline Cystosarcoma phylloides & 1 & - & 1 & - \\
\hline Galactocele & 2 & - & - & - \\
\hline Breast abscess & - & - & - & 2 \\
\hline Gynaecomastia & - & 1 & - & - \\
\hline Antibioma & 1 & - & - & - \\
\hline Sclerosing adenosis & 1 & - & - & - \\
\hline Ductual hyperplasis & 1 & - & - & - \\
\hline Total & $\mathbf{3 1}$ & $\mathbf{1}$ & $\mathbf{1}$ & $\mathbf{2}$ \\
\hline Percentage & $\mathbf{6 2 \%}$ & $\mathbf{2 \%}$ & $\mathbf{2 \%}$ & $\mathbf{4 \%}$ \\
\hline
\end{tabular}

Of the 50 cases simple excision of the lump was performed in $31(62 \%)$ of cases. Subcutaneous mastectomy was done in the solitarycase of gynaecomastia. Simple mastectomy was resorted to treat a case of huge cystosarcomaphylloides. Incision and drainage was done for two cases of breast abscess due to duct ectasia. 
Follow-Up

Table XII Follow up and recurrence

\begin{tabular}{|l|c|}
\hline Symptoms & No. of cases \\
\hline Breast Pain & $5 / 20$ \\
\hline Lumpiness & $4 / 12$ \\
\hline
\end{tabular}

A total of 20 patients were available for followup. The follow up period ranged from three to eighteen months, 9 of the patients followed up had symptoms related to breast disease, 5 complained of breast pain, 4 had lumpiness of the breast, 5 were noted to have a small lump, which was treated conservatively, showed no increase in size. There was no recurrence in simple cysts, which were aspirated. One case of gynaecomastia managed conservatively showed spontaneous regression.

\section{Discussion}

A total of 50 cases of benign breast disease were studied upon during the two-year period (March 1999 to Feb 2001). The spectrum of the disease remained more or less uniform throughout the study period. Benign breast disease occurs predominantly in women during reproductive life. Fibroadenoma tends to occur in younger women compared to fibroadenosis ${ }^{11}$. Whichpresents more frequency in the perimenopausal women. This is thought to be related to the anovulatory menstrual cycles during this period. In the current study. $46 \%$ of the lesions (Table-t) occurred in the third decade of life, whereas $10 \%$ and $24 \%$ presented in the fourth and second decades respectively. Tibor Decholnoky ${ }^{28}$ reported a similar age distribution, while in J. C. Cuptaro study, $85 \%$ of the patient were in the age group of twelve to forty years.

$24 \%$ of the patients were teenagers in this study. Majority (89\%) of them had fibroadenomas whereas less than $5 \%$ had fibroadenosis. A study from West Indies ${ }^{17}$ showed that $25 \%$ of the benign breast lumps occurred in the teenage group, while a study from Jabalpurlo ${ }^{10}$ reported for $33 \%$. In this study $70 \%$ of the fibroadenoma presented in the age group of 11 to 30 years. The corresponding figures in literature include $70 \%$ reported by Haagensen $^{11}$ and $82 \%$ in a study from Madras ${ }^{20}$. Almost $100 \%$ of the patients with fibroadenosis were between 20 and 40 years average age being a decade more compared to fibroadenoma.

About $11 \%$ of the fibroadenosis patients in this study presented in the second decade compared to $3 \%$ recorded by Startwell $^{24}$. Regarding benign cystosarcomaphylloides the patients we had, presented at the age of 35 to 40 years. Haagensen ${ }^{11}$ found $60 \%$ of his patient to be aged between third and fifth decade of life.

Over $40 \%$ of women are said to have evidence of fibroadenosis at some time or the other during their lifetime ${ }^{30}$. Although fibroadenosisis such a common lesion of the breast, it is seldom operated on. Thus, in this study, fibroadenosis form only $20 \%$ of the cases white fibroadenoma accounts for $54 \%$ of the cases (Table - II). These findings are consistent with J.C. Gupta et $\mathrm{al}^{10}$ who found that fibroadenomas and fibroadenosis constituted $64 \%$ and $22 \%$ respectively, of the fibroadenomas and fibroadenosis constituted $64 \%$ and $22 \%$ respectively of the benign breast lumps in the Jabalpur area. Rangabashyam ${ }^{20}$ reported a similar incidence at Madras while Oluwole et $\mathrm{al}^{27}$ reported similar figures in American black.

In most of the studies from the west, gross cysts or macrocysts are commonest benign breast lumps, However in the current study, two gross cysts were encountered. J. C, Gupta et $\mathrm{al}^{10}$ also did not encounter, many gross cyst in his study.

\section{Etiology}

In the prospective study an attempt was made to find the prevalence of use of oral contraceptives among the patients. However, there was no control group and so definite conclusion, are not possible. The controversy regarding the association of oral contraceptives and benign breast disease still rages on in the west ${ }^{30}$. Initial studies showed a beneficial effect of oral contraceptives in reducing benign breast disease later studies, using newer formulations of oral pills, failed to corroborate these findings. The extremely low prevalence i.e. $20 \%$ of use of oral pills in the present study does not permit any meaning full conclusion. 


\section{Clinical Features}

In the present study, $68 \%$ of the patients had symptoms of less than one-year duration. The duration ranged from one week to twenty years (Table III). These figures are in agreement with Tibor Decholnoky's ${ }^{28}$ study. As in most studies, the presence of a breast lump was the commonest symptom $(80 \%)$ of the cases. pain was present in $24 \%$ of The patients. Tibor Decholnoky, ${ }^{28}$ noted pain in $55 \%$ of his patients. In the present study, $80 \%$ of the patients with fibroadenosis had pain. In the present study, nipple discharge from the patients was present in only $8 \%$ of the patients. Tibor Decholnoky,s had no patients with nipple discharge (Table - IV). Duct papillomas most commonly present with nipple discharge, whereas this symptom was less common in fibroadenosis and rare in fibroadenoma

None of the patients in the present study gave any history of reduction in size or disappearance of breast lumps. But 5 cases treated conservatively in this study, showed no progression in size of the lump, though regression in the size was not seen. This is in contrast to Wilkinson ${ }^{32}$ who noted spontaneous resolution of fibroadenoma in $16 \%$ of his patients. It is generally accepted that upto $10 \%$ of fibroadenomas less than $2 \mathrm{~cm}$ in size regress spontaneously. The later presentation and larger average size in the present study as compared to the west may account for the absence of spontaneous resolution.

In the present study, details of menstrual and obstetric history were available for almost all the cases, 6ryo of the patients were nulliparous compared to the $650 / 0$ noted by Tibor Decholnoky's $^{28}$ and $21 \%$ by Sartwell ${ }^{24}$. The difference may be due to the early marriage in our country. Menstrual abnormalities were noted in $20 \%$ of the cases in the present study. These were uniformly distributed among the various sub groups. In this present study, only 4 women who were postmenopausal. Benign breast disease in rare after the reproductive years. It is generally felt that benign breast lumps must have originated in the premenopausal age but came to notice only after menopause. The duration of lump in this group on an average was three years compared to with less than one year in the premenopausal age. There was a mild preponderance of lesions in the right breast in this study. The difference is however, not significant. $50 \%$ of the lesions were located in the upper and outer quadrant of the breast. Tibor Decholnoky's ${ }^{28}$ noted that $50 \%$ of the lump in his study were in this quadrant of the breast, while Oluwole et $\mathrm{al}^{27}$ found $60 \%$ of the lumps at this site. This finding is related to the large amount of breast parenchyma in this quadrant as compared to the others. Multiple Lumps were present in $18 \%$ of the patients in this study. This is slightly higher than the $17 \%$ reported by Geschickters $^{9}$ and $16 \%$ each in both Oliver's and Haagensen's studies. A study from Madras ${ }^{20}$ found multiple lumps in $27 \%$ of cases. The distribution of multiplicity among the major sub groups was uniform.

Majority of the lumps (54\%) in the present study averaged 2 to $5 \mathrm{cms}$ in size (Table - III). Benign breast lumps, especialty fibroadenomas progress slowly after attaining a size of $2 \mathrm{~cm}$. Tibor Decholnoky's $^{28}$ study showed that $57 \%$ of the benign lumps were less than $2 \mathrm{~cm}$ whereas the corresponding figure in the current study was $24 \%$. The late presentation, which is common in our country, may explain this wide disparity and the lack of spontaneous resolution noted in this study. It is common that benign cystosarcomaphylloides always present with large masses. But Ilaagensen ${ }^{11}$ emphasized that $28 \%$ of his cases were less than $5 \mathrm{~cm}$, In the present study we came across two cases which was more than $15 \mathrm{~cm}$. Giant fibroadenoma had been defined by Block ${ }^{1}$ as a fibroadenoma occupying a major portion of the breast or weighing more than $500 \mathrm{gms}$. Two cases of galactocele presented with firm masses in the breast within 6 months of cessation of lactation. The two cases of mammary duct ectasia presented with complications such as abscess. Antibioma of the breast presented as hard mass mimicking malignancy. No case of tuberculosis or filariasis was not included. Rangabashyam et $\mathrm{al}^{20}$ 
found 5 cases of filarial breast in a five-year study from madras.

\section{Fine Needle Aspiration Cytology (Table IX)}

This investigation was done in almost all the cases, basically to clear the doubts of clinical diagnosis. $81.5 \%$ of fibroadenoma could be diagnosed correctly by FNAC, whereas 7oolo of fibroadenosis were diagnosed. Inflammatory lesions (Antibioma) were detectable by FNAC. The key role of FNAC in the management of benign breast lesions is to rule out malignancy. The further segregation into the subtypes with FNAC may not be very important in management. However, in combination with clinical examination and mammography, it aids in the conservative management of small lumps or postpone surgery in younger patients and also in avoiding surgery for fibroadenosis.

\section{Surgical Treatment (Table - XI)}

Majority of the benign lumps underwent simple excision of lumps (62\%).

Subcutaneous mastectomy was performed in the solitary case of gynaecomastia preserving nipple and areolar complex. A case of cystosarcoma phylloides occupying the entire breast underwent simple mastectomy, Calactocele had to be excised in two patients. These treatment modalities are in agreement with accepted principles. The correlation between clinical and histopathological diagnosis was best for fibroadenoma. The figure $76 \%$ in this study agrees well with the $75 \%$ reported by Wilkinson. A clinical diagnosis of carcinoma breast was considered in $8 \%$ of the cases of fibroadenosis, $3 \%$ of the fibroadenoma, two cases of antibioma. These figures may be explained by the older age of the patients with fibroadenosis and the hardness of the lumps in antibioma.

\section{Follow, up and recurrence (Table - XII)}

20 of the patients were followed up for periods ranging from three to eighteen months. While many of these had complaints regarding breast disease only.
There was no recurrence of fibroadenoma in our series. Recurrence in Ilaagensen's series ${ }^{11}$ is $16 \%$. The follow up may account for this difference. In the teenage group, there was no relationship noted in the present study between the size and number of fibroadenoma to recurrence.

Retrospective study from the West Indies $^{27}$ recommends observation of fibroadenomas in teenagers as up to $10 \%$ may resolve spontaneously and another $10 \%$ may develop multiple lumps necessitating repeat surgery. Ilaagensen also recommends that fibroadenomas less than $5 \mathrm{~cm}$ in size in young women may be followed up. But, 5 cases of fibroadenomas managed conservatively in our series did not show progression. None of the patients had any regression of lumps. However, the present study suffers from the drawback of lacking a control group and short follow up. A prospective study with a Longer follow up period is necessary to reach definite conclusions.

The patients with benign cystosarcoma phylloides could not be followed up. Chua etala reported a recurrence of $15.8 \%$ in his study of benign cystosarcoma. The generally accepted figures for recurrence in these cases is 2001o. The reason for the recurrence is that small cystosarcoma are mistaken for fibroadenomas and excised without a adequate margin $(.2 \mathrm{~cm}$ is now recommended). Intraoperative frozen section biopsy is being recommended by some authors to detect cystosarcoma in doubtful cases. FNAC also could be utilized for this purpose. The histopathology of benign cystosarcoma does not change with recurrence in the majority of instance.

\section{Conclusion}

The findings of this clinico-pathological study of benign breast lumps collaborates with the findings of earlier works in most aspects, but differs with respect to the management of fibroadenomas in teenagers.

The conclusions are as follows:

- The commonest benign breast lesion encountered in the present study was 
fibroadenontas constituting $54 \%$ followed by fibroadenosis in $20 \%$

- Fibroadenoma presents most often in the second and third decades, while fibroadenosis presents a decade later.

- Although, fibroadenosis is common in the general population, it is the fibroadenoma, which are operated upon more often.

- The mode of presentation is almost always with a lump in the breast associated often with pain but seldom with discharge, the exception being duct papilloma.

- Galactocele was the third most common breast lesion in this study.

- The other benign lesions such as sclerosingadenosis, duct hyperplasia and duct ectasia etc. were mostly diagnosed at histopathology; lesions such as antibioma were commonly mistaken for malignancy.

- There was no recurrence during period of followup and no malignant transformation in any benign breast disease.

- No definite conclusions could be drawn from this study on the use of oral contraceptives. No spontaneous regression of benign breast lumps were noticed during this study, especially with regards to fibroadenoma. In addition fibroadenomaare a great source of great anxiety in the teenage period. In view of these facts, fibroadenomain teenagers are probably better dealt by surgery.

- Health education, awareness, literacy can help in early detection ofbreast disease and appropriate therapy.

- Breast self-examination as advised by Haagensen is good method of early diagnosis of lesions.

\section{Reference}

1. Block G. E. and Zlantnik P. A.: Ciantfibroadenomata of the breast in a prepubertal gifl. Archives of Sugery, I9B5: $80,673$.
2. Bundre's. S. J.r Aetiology of Benign breast disease. British Joumal of Sutgery, 1994: June 81 (6), 748-789.

3. Cant P. J. and Madden M. V. et aI: Case for conservative Management of selected fibroadenomas of the brcasL. British Journal of Sulgery. I9871 74, 5A7,

4. Chua C. Lr Cystosarcoma Phylloides - A review of surgical option, Surg., 1988r 10s. 141.

5. Das C.: Clinical methods in Surgery, Calcutta, 1996:508-j21.

6. Davis fl. N., Simon M. and Davis J. B.r cystic disease of the breast, Relationship to cancer. Cancer, 1964.17,9b.

7. David C. Sebastin Jr.: Textbook of Surgery, 15,h Edition W. B. Saunders, 1997: 55a-56a

8. Dixon et al 'Reduction ol the surgical excision rate of benign breast disease using fine needle aspiration cytology and immediate reporting,. British Journal of Sllrgery. tov. 1987: Vol. 74.

9. Geschitcekter C. F. : Diseases oF the breast. Second Edition_Philadetphia, J. B. Lippincott, $\mathrm{t} 948$.

10. Gupta J. C et aI: Breast lumps in Jabalpur area - Review of 1104 cases fndian Journal of Surgery, $\operatorname{tg} A Z: 45,26 \mathrm{~A}$

11. tlaagensen C. D.: Diseases of the breast, W. B. Saunders. Third Edition, 19a6, 146, 267-2A3, 576

12. tlughes L. E.: Recent advances in Surgery. Churchill Livingstone, 1982, Vol. I 1.

13. Hughes L. E.: Introduction to benign breast disease, World Journal of Surgery, 19B9: $15,667$.

14. Johnson C. D., Taylor I.: Recent advances in Surgery, Churchill Livingstone, I998, Vol. Zl: 71-AO.

15. Juan Rosai Ackerman's Surgical pathology, Eight Edition, Mosby, 1996: Vol. 2, 1565-1590. 
16. Morris \&Mattt Oxford Textbook of Surgery, 1994, Oxford Medical Publications, 792-aO7.

17. Narayan Singh v. and Raju et al: TrealmentoF breast lumps in the teenager. Briiish Journal ol Surgery, 19A7: 74, I 16 .

18. Page \&Dupont: Atypical hyperplastic lesions of the female breast - A long-terrnfollowup study. Cancer, I9a5r 55,269a.

19. Preece, llughes L. E. and Mansel: Clinical syndromes of mastalgia, Lancet, 1976: Vol. 2, 67O

20. Rangabhashyam N., cnanaprakasam D. and Krishnaraj B.: Spectrum of benign breast lesion in Madras JoLrmal of Royal Coltege of Surgeons, Edinburg, 1983: 28, 569.

21. Rintoul R. F.: Farquharson's Textbook of Operative Surgery, Eight Edition, Churchill Livingstonc, 19a5: 3.51 J55.

22. Robert G. Somer. ceraldine P. et al: Fine needle aspiration biopsy in the management ol the solid breaslLumors. Archives of Surgery, I985: t20,673.

23. Russel R. C. c: Bailey \& Love's Short practice of Surgery, 23rd Edition, Amold Publications, 2OOO: 7 49-760.

24. Sartwell P. E. Arthes F. G..Tonascia J.: Epidemiology of benign breast lesions, New England Journal of Medicine 197 3t 2AA, 551,

25. Seymour I. Sclrvrartz. Flanc Spencer and Tom Shires: Pdnciples of Surgery, Sixth Edition, Mc. Craw Hill lnc., 19941 54A552.

26. ShuklatI. S. and Kumar S.: Benign breast disease in India, World Journalof Surgery, t9A9: 13, 667.

27. Soju F. Oluwole and tlaiold P. Irteeman: Analysis of benign breast disease lesions in blacks. American Journal of Surgery.1979: Vol. 157, 7 a6-7 49.

28. Tibor Decholnoky: Benign tumors of the breast, Archives of Surgery: 1937: 34. '79.
29. Treaves and Sonderlandr Cystosarcoma Phylloides - A malignant and benign tumors, Aclinico pathological study of 77 cases. Cancer., I951: 4, | 49.

30. Vess $€$ y M- P. and Sutton p. M.: Oral conlraceptives and breast neoplasia - A relrospeclive study. British Medical Journat, $\lg 72 \mathrm{t}$ Vol, S, 7 t9.

31. Vetto J. Pommer R., Schmidt W. et al Triple test for palpable breast lesions. American Journal of Surgery, I 995 r 169, 519-522.

32. Wilkinson S, Anderson J.: Fibroadenoma of the breast - A followup of conseryative management. British Journal of Surgery, $\lg$ 'St 72, BSA. 